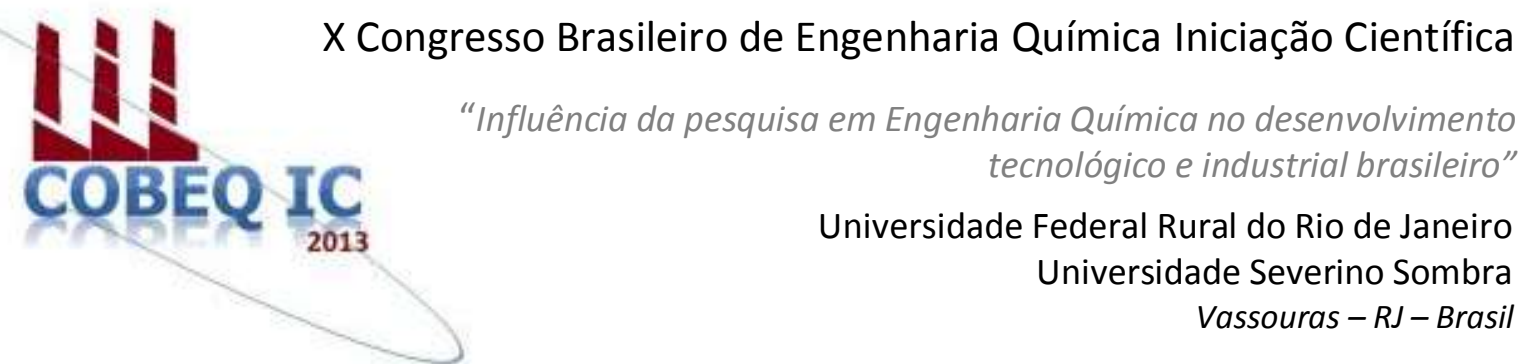

\title{
ANÁLISE DAS PROPRIEDADES FUNCIONAIS PROTÉICAS DA Spirulina sp. SECA EM LEITO DE JORRO
}

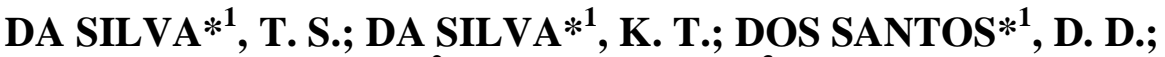 \\ LARROSA ${ }^{2}$, A. P. Q.; PINTO ${ }^{3}$, L. A. A. \\ ${ }^{1}$ Alunas da EQA/FURG ${ }^{2}$ Doutoranda do PPG-ECA/FURG ${ }^{3}$ Professor da EQA/FURG \\ Escola de Química e Alimentos - Universidade Federal do Rio Grande \\ Rua Alfredo Huch, 475 - CEP 96.201-900 - Rio Grande, RS \\ email: dqmpinto@furg.br
}

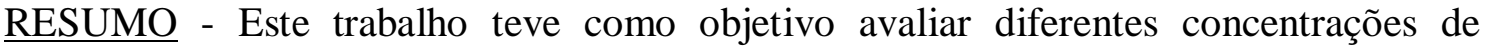
sólidos (5 e 8\%) de biomassa de Spirulina sp. e temperaturas do ar de secagem (80 e $100^{\circ} \mathrm{C}$ ) nas propriedades funcionais e nutricionais das proteínas do produto desidratado. Foi utilizada a microalga Spirulina sp. Leb-18, cultivada em fotobiorreatores abertos em condições não controladas. Os experimentos foram conduzidos em um leito de jorro de geometria cônica, utilizando uma taxa de alimentação de $0,4 \mathrm{~kg}_{\text {pasta. }} \cdot \mathrm{kg}_{\text {. inerte }}{ }^{-1} \cdot \mathrm{h}^{-1}$, e partículas de polietileno como inertes. O produto final foi avaliado quanto à umidade, proteína, solubilidade protéica e digestibilidade in vitro. Os resultados mostraram que o teor de proteína da Spirulina seca em leito de jorro foi de 59,2 $\pm 0,2 \%$, a umidade ficou na faixa comercial (abaixo de 10\%). A solubilidade protéica das amostras secas em leito de jorro em relação à biomassa in natura apresentou um aumento de 18 a 98\%, enquanto que a digestibilidade in vitro aumentou de 25,7 a $47 \%$. O experimento realizado a $100^{\circ} \mathrm{C}$ utilizando uma biomassa com $5 \%$ de sólidos apresentou melhores resultados.
\end{abstract}

Palavras chave: digestibilidade, microalga, solubilidade.

\section{INTRODUÇÃO}

A pesquisa biotecnológica de microalgas vem crescendo ultimamente devido à identificação de diversas substâncias sintetizadas por estes organismos. Os cultivos de microalgas têm sido realizados visando à produção de biomassa, tanto para uso na elaboração de alimentos quanto para a obtenção de compostos naturais com alto valor no mercado mundial (Derner et al., 2006). As cianobactérias são as microalgas mais estudadas e cultivadas, com destaque às espécies do gênero Spirulina (Becker et al., 2004).

A Spirulina é uma cianobactéria, chamada de Arthrospira platensis ou comumente chamada de alga azul-verde, filamentosa e espiralada (Desmorieux e Decaen, 2006). É uma microalga amplamente conhecida e utilizada mundialmente, que cresce rapidamente em meio alcalino, sendo uma boa fonte proteica de alta digestibilidade, contendo em torno de 50 a $70 \%$ de proteínas, 
fonte de compostos antioxidantes e de ácidos graxos essenciais como o $\gamma$-linolênico. (Vonshak, 1997; Ambrosi et al., 2008).

A secagem é uma operação unitária que tem sido utilizada para obtenção de biomassa a fim de aumentar a vida útil, minimizando o crescimento microbiano, deteriorações por reações químicas, além da facilidade de transporte e estocagem pela redução de peso e volume (Oliveira et al., 2010). Dentre as técnicas de secagem que têm sido utilizadas para obtenção de biomassa de Spirulina podem-se citar spray drying, freeze-drying, secagem solar, e secagem convectiva (Show et $a l .$, 2013). Além disso, a secagem em leito de jorro é uma técnica de baixo custo de operação e manutenção em relação ao spray drying, e tem obtido resultados promissores na qualidade do produto final. Essa técnica possui diversas aplicações, tais como o recobrimento de partículas e a secagem de pastas e suspensões, porém a secagem de Spirulina em leito de jorro ainda é pouco explorada.

A qualidade de um alimento é definida pela sua composição, suas propriedades nutricionais e suas propriedades funcionais. As propriedades funcionais são aquelas na qual qualquer propriedade de um componente de um alimento, excetuando-se as nutricionais, influencia a sua aceitação e utilização. A avaliação dessas propriedades, como a solubilidade protéica, possui grande importância na formulação de produtos alimentícios, de forma que ocorra uma interação da proteína com outros componentes, contribuindo na formação da textura nos alimentos (Sgarbieri, 1996; Krüger et al., 2002).

Além do aspecto qualitativo da proteína, deve também ser considerado seu valor nutritivo, que depende da sua composição, digestibilidade, biodisponibilidade de aminoácidos essências e ausência de fatores antinutricionais e substâncias tóxicas (Sgarbieri, 1996).

Como na secagem em leito de jorro de pastas e suspensões, as condições operacionais influenciam nas características do produto final, este trabalho teve como objetivo avaliar diferentes concentrações de sólidos de biomassa de Spirulina sp. e temperaturas do ar, nas propriedades funcionais e nutricionais das proteínas do produto desidratado.

\section{MATERIAL E MÉTODOS}

\section{Matéria-prima}

Foi utilizada Spirulina $s p$. LEB-18 (Morais e Costa, 2007) cedida pelo Laboratório de Engenharia Bioquímica da FURG/RS. A microalga foi cultivada em meio sintético Zarrouk (Zarrouk, 1966) em condições não controladas em fotobiorreatores, na cidade de Santa Vitória do Palmar (RS). A biomassa foi obtida por filtração direta e prensada, contendo $15 \%$ de sólidos.

\section{Secagem em leito de jorro}

A biomassa de Spirulina sp. foi seca em leito de jorro de geometria cônica com diâmetro de célula de $17,5 \mathrm{~cm}$, base cônica (superior e inferior) com ângulo incluso de $60^{\circ}$ e altura de $15 \mathrm{~cm}$. Foi utilizado um suporte de inertes constituído por partículas de polietileno com uma carga de $0,5 \mathrm{~kg}$, diâmetro médio de $3,2 \mathrm{~mm}$, esfericidade de 0,7 e densidade de $0,96 \mathrm{~g} \cdot \mathrm{cm}^{-3}$.

As medidas de vazão de ar foram realizadas por meio de uma placa de orifício acoplada a um manômetro de tubo em " $U$ " e, as temperaturas (entrada, saída) do ar foram medidas por termopares cobre-constantan.

A biomassa foi alimentada por meio de uma seringa plástica, sendo atomizada com ar comprimido à uma pressão de $200 \mathrm{kPa}$ abs. A taxa de circulação de sólidos foi de $100 \%$ acima da velocidade de jorro mínimo. O produto desidratado era recolhido em um recipiente de vidro acoplado ao ciclone do tipo Lapple, para realização das análises.

$\mathrm{O}$ esquema do equipamento utilizado na secagem de Spirulina sp. está apresentado na Figura 1: 


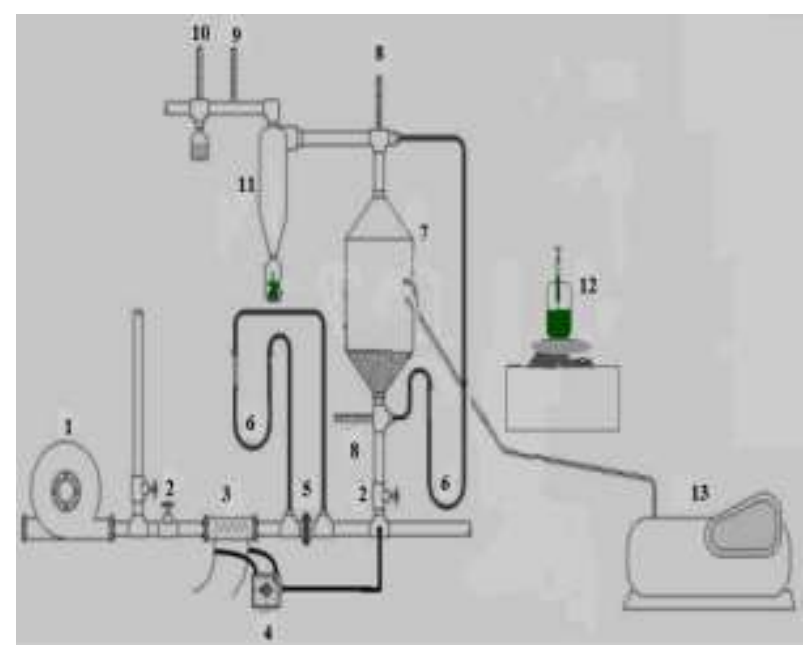

Figura 1 - Esquema do equipamento experimental de secagem em leito de jorro.

Legenda: (1) soprador radial, (2) válvulas, (3) sistema de aquecimento, (4) controlador de temperatura, 5) placa de orifício, (6) manômetro de tubo em "U”, (7) célula de secagem, (8) termopares de entrada e saída, (9) termopar de bulbo seco, (10) termopar de bulbo úmido, (11) ciclone tipo Lapple, (12) reservatório da pasta, (13) compressor de ar.

Os experimentos em leito de jorro foram realizados em duas temperatura do ar de entrada $\left(80\right.$ e $\left.100^{\circ} \mathrm{C}\right)$ e de duas concentração de sólidos na pasta de biomassa (5 a $8 \%$ ). A vazão de alimentação foi fixada a $200 \mathrm{~mL} \cdot \mathrm{h}^{-1}$, definida por testes preliminares. Foi realizado um tratamento de dados, estudando os efeitos da temperatura do ar de entrada e da concentração de sólidos da biomassa nas propriedades funcionais e nutricionais da Spirulina sp. (LEB-18), como a solubilidade protéica e digestibilidade protéica in vitro.

\section{Metodologia Analítica}

A umidade das amostras seca e in natura da biomassa foi analisada pela metodologia $\mathrm{n}^{\circ} 926.10$ da A.O.A.C. (1995). A proteína foi determinada pelo método de Kjeldhal n 960.20 da A.O.A.C. (1995).

A solubilidade protéica em meio aquoso foi avaliada segundo o método de Morr et al. (1985). A digestibilidade proteica in vitro, foi analisada segundo método de Sgarbieri (1996).

\section{Metodologia estatística}

As respostas avaliadas como umidade, proteína, solubilidade protéica e digestibilidade protéica, foram analisadas estatisticamente através do Teste de Tukey ao nível de $95 \%$ de confiança $(\mathrm{p}<0,05)$.

\section{RESULTADOS E DISCUSSÃO}

As amostras de Spirulina sp. secas em leito de jorro e a in natura foram comparadas estatisticamente na Tabela 1 pelas respostas umidade e teor de proteína.

Tabela 1 - Umidade e teor de proteína das amostras in natura e seca em leito de jorro.

\begin{tabular}{ccc}
\hline Amostra & $\begin{array}{c}\text { Umidade } \\
(\% \text { b.u. })^{*}\end{array}$ & $\begin{array}{c}\text { Proteína } \\
(\%) \cdot \text {. }^{*}\end{array}$ \\
\hline $\begin{array}{c}80^{\circ} \mathrm{C} \text { e } 5 \% \\
\text { sólidos }\end{array}$ & $9,8 \pm 0,2^{\mathrm{a}}$ & $58,9 \pm 2,1^{\mathrm{a}}$ \\
$\begin{array}{c}100^{\circ} \mathrm{C} \text { e } 5 \% \\
\text { sólidos }\end{array}$ & $9,1 \pm 0,5^{\mathrm{a}, \mathrm{b}}$ & $59,2 \pm 0,7^{\mathrm{a}}$ \\
$\begin{array}{c}80^{\circ} \mathrm{C} \text { e } 8 \% \\
\text { sólidos }\end{array}$ & $9,3 \pm 0,8^{\mathrm{a}, \mathrm{b}}$ & $60,1 \pm 1,0^{\mathrm{a}}$ \\
$\begin{array}{c}100^{\circ} \mathrm{C} \text { e } 8 \% \\
\text { sólidos }\end{array}$ & $8,8 \pm 0,2^{\mathrm{b}}$ & $58,6 \pm 1,6^{\mathrm{a}}$ \\
\hline In natura & $92,0 \pm 0,5^{\mathrm{c}}$ & $5,3 \pm 0,1^{\mathrm{b}}$
\end{tabular}

\footnotetext{
*Valor médio \pm erro médio. Letras diferentes na mesma coluna apresentam diferença significativa $(p<0,05)$; b.u.: base úmida.
}

Analisando os resultados obtidos na Tabela 1, observa-se que as umidades das amostras secas ficaram abaixo de 10\% (na faixa comercial). Em relação ao teor de proteína, observa-se que ficou próximo de $60 \%$, de acordo com a literatura que indica uma faixa de 50 a $70 \%$ (Vonshak, 1997; Ambrosi et al., 2008).

Em relação à biomassa in natura, observa-se que o teor de proteína ficou abaixo do esperado, devido à diluição realizada para secar em leito de jorro, visto que a concentração de sólidos influencia o comportamento do leito. A biomassa prensada apresentou em torno de $12,4 \pm 0,4 \%$ de proteína com umidade de $75 \%$ (b.u.).

A Tabela 2 mostra os resultados da solubilidade protéica e digestibilidade protéica da biomassa in natura e seca em leito de jorro. 
Tabela 2 - Resultados de solubilidade protéica em meio aquoso e digestibilidade protéica in vitro das amostras de Spirulina in natura e seca em leito de jorro.

\begin{tabular}{|c|c|c|}
\hline Amostra & $\begin{array}{c}\text { Solubilidade } \\
(\%)^{*}\end{array}$ & $\begin{array}{c}\text { Digestibilidade } \\
(\%)^{*}\end{array}$ \\
\hline $\begin{array}{c}80^{\circ} \mathrm{C} \text { e } 5 \% \\
\text { sólidos }\end{array}$ & $45,5 \pm 1,9^{\mathrm{a}}$ & $31,8 \pm 0,5^{\mathrm{a}}$ \\
\hline $\begin{array}{c}100^{\circ} \mathrm{C} 5 \% \\
\text { sólidos }\end{array}$ & $56,2 \pm 1,6^{b}$ & $28,4 \pm 1,0^{b}$ \\
\hline $\begin{array}{c}80^{\circ} \mathrm{C} \text { e } 8 \% \\
\text { sólidos }\end{array}$ & $33,4 \pm 2,4^{\mathrm{c}}$ & $33,3 \pm 0,7^{\mathrm{c}}$ \\
\hline $\begin{array}{c}100^{\circ} \mathrm{C} \mathrm{e} \\
8 \% \text { sólidos }\end{array}$ & $49,9 \pm 0,6^{\mathrm{d}}$ & $32,5 \pm 1,6^{\mathrm{a}, \mathrm{c}}$ \\
\hline In natura & $28,3 \pm 3,8^{\mathrm{c}}$ & $22,6 \pm 2,5^{\mathrm{d}}$ \\
\hline
\end{tabular}

Observa-se na Tabela 2, que a solubilidade protéica em meio aquoso apresentou diferença significativa ao nível de $5 \%(\mathrm{p}<0,05)$, onde nota-se que em relação à amostra in natura obteve um aumento da solubilidade de 18 a 98\%. Além disso, a solubilidade foi maior na temperatura mais elevada, sendo que na condição de $100^{\circ} \mathrm{C} \mathrm{com}$ concentração de sólidos de 5\% apresentou maior solubilidade. Apesar da temperatura de saída ter sido mais elevada $\left(82^{\circ} \mathrm{C}\right)$, é importante ressaltar que o produto sai do secador a uma temperatura um pouco acima de bulbo úmido. Segundo Sgarbieri (1996), a solubilidade das proteínas aumentam em temperaturas entre 40 a $50^{\circ} \mathrm{C}$, e como a temperatura do bulbo úmido na condição em que obteve a maior solubilidade estava a $37 \pm 1^{\circ} \mathrm{C}$, justifica o aumento dessa propriedade em relação à biomassa in natura.

Em relação à digestibilidade, as amostras apresentaram diferença significativa ao nível de $5 \%(\mathrm{p}<0,05)$ em relação à amostra in natura, onde a propriedade nutricional aumentou com a secagem de 25,7 a $47 \%$. Isso pode ser explicado devido às proteínas terem sofrido alguma mudança na sua conformação com o tratamento térmico, aumentando a susceptibilidade à proteólise

\section{CONCLUSÃO}

Os resultados mostraram que o teor de proteína da Spirulina seca em leito de jorro foi em torno de $60 \%$ e a umidade ficou na faixa comercial (abaixo de 10\%).

A solubilidade protéica das amostras secas em leito de jorro em relação à biomassa in natura apresentou um aumento de 18 a $98 \%$, enquanto que a digestibilidade in vitro aumentou de 25,7 a $47 \%$.

Diante dos resultados, pôde-se definir que a condição experimental utilizando temperatura do ar de entrada de $100^{\circ} \mathrm{C}$ e concentração de $5 \%$ de sólidos da biomassa, proporcionou melhores resultados nas propriedades funcionais e nutricionais das proteínas da Spirulina.

\section{REFERÊNCIAS}

AMBROSI, M. A., REINEHR, C. O., BERTOLIN, T. E., COSTA, J. A. V., COLLA, L. M. (2008), Propriedades de saúde de Spirulina spp. Revista de Ciências Farmacêuticas Básica Aplicada, 29 (2), 109-117.

AOAC. (1995) ASSOCIATION OF OFFICIAL ANALYTICAL CHEMISTS , Official Methods of Analysis. 14 ${ }^{\mathrm{a}}$ ed., v. 1.

BECKER, E. W. (2004), Microalgae in human and animal nutrition. In: RICHMOND, A. (Ed). Handbook of microalgal culture: biotechnology and applied phycology. London: Blackwell Science, p.312-351.

DERNER, R. B., OHSE, S., VILLELA, M., CARVALHO, S. M., FETT, R. (2006), Microalgae, products and applications. Ciência Rural, 36 (6), 1959-1967.

DESMORIEUX, H., DECAEN, N. (2006), Convective drying of Spirulina in thin layer. Journal Food Engineering, 77, 6470.

KRÜGER, C., CENI, G., SGARBIERI, V., CÂNDIDO, L. (2002), Propriedade hidrofílica de concentrados proteicos de leite bovino. Boletim da Sociedade Brasileira de Ciência e Tecnologia de Alimentos, 36 (2), 122-127. 
MORAIS, M. G., COSTA, J. A. V. (2007), Carbon dioxide biofixation with Chlorella kessleri, C. vulgaris, Scenedesmus obliquus and Spirulina sp. cultivated in flasks andvertical tubular photobioreactors. Biotechnology Letters, Rio Grande, 29 (9), 1349-1352.

MORR, C. V., GERMAN, B., KINSELA, J. E., REGENSTEIN, J. M., VAN-BUREN, J. P., KILARA, A., LEWIS, B. A., MAGNINO, M. E. (1985), Collaborative study to develop a standardized food protein solubility procedure. Journal of Food Science, 50, 1715-1718.

OLIVEIRA, E. G., DUARTE, J. H., MORAES, K., CREXI, V. T., PINTO, L. A. A. (2010), Optimisation of Spirulina platensis convective drying: evaluation of phycocyanin loss and lipid oxidation. International Journal of Food Science and Technology, 45, 1572-1578.

SGARBIERI, V. C. (1996), Proteínas em alimentos proteicos: propriedades, degradações, modificações. Editora e Livraria Varela, São Paulo, SP.

SHOW, K. Y., LEE, D. J., CHANG, J. S. (2013), Algal biomass dehydration. Bioresource Technology, 135, 720-729.

VONSHAK, A. (1997), Spirulina Platensis (Arthrospira) Physiology, Cell- Biology and Biotechnology. London: Taylor \& Francis.

ZARROUK, C. (1966), Contribution A ' L'e'tude D'une Cyanophyce'e. Influence De Divers Facteurs Physiques Et Chimiques Sur La Croissance Et $\mathrm{La}$ Photosynthe`se De Spirulina Maxima. Ph.D. Thesis. Paris, France: University of Paris.

\section{AGRADECIMENTOS}

Os autores deste trabalham agradecem à CAPES e a FURG pelo apoio financeiro, e ao Laboratório de Engenharia Bioquímica (LEB) da FURG/RS. 